\title{
Ice-covered Lake Onega: effects of radiation on convection and internal waves
}

\author{
Damien Bouffard • Roman E. Zdorovennov • \\ Galina E. Zdorovennova • Natacha Pasche • \\ Alfred Wüest · Arkady Y. Terzhevik
}

Received: 14 December 2015/Revised: 28 June 2016/Accepted: 8 July 2016/Published online: 17 August 2016

(C) Springer International Publishing Switzerland 2016

\begin{abstract}
Early-spring under-ice convection in the Petrozavodsk Bay of Lake Onega (Russia) was investigated as part of an interdisciplinary research project conducted during March 2015. Measurements performed using a thermistor chain and vertical profiling sensors were used to examine temperature dynamics in the convectively mixed and stratified layers of the lake. Radiative transfer through the ice was high leading to a large convective mixed layer (up to $20 \mathrm{~m}$ deep) during daytime. Convective velocity
\end{abstract}

Guest editors: Paula Kankaala, Tiina Nõges, Martti Rask, Dietmar Straile \& Arkady Yu. Terzhevik / European Large Lakes IV. Ecosystem Services and Management in a Changing World

Electronic supplementary material The online version of this article (doi:10.1007/s10750-016-2915-3) contains supplementary material, which is available to authorized users.

D. Bouffard $(\bowtie) \cdot$ N. Pasche $\cdot$ A. Wüest

Physics of Aquatic Systems Laboratory, Margaretha

Kamprad Chair, EPFL-ENAC-IEE-APHYS,

1015 Lausanne, Switzerland

e-mail: damien.bouffard@epfl.ch

R. E. Zdorovennov · G. E. Zdorovennova ·

A. Y. Terzhevik

Karelian Research Center, Northern Water Problems

Institute, Russian Academy of Sciences, Moscow, Russia

\section{A. Wüest}

Eawag, Swiss Federal Institute of Aquatic Science and

Technology, Surface Waters - Research and

Management, Kastanienbaum, Switzerland was evaluated using two different methods. It is shown that convective velocity (a maximum value of $\sim 7.4 \mathrm{~mm} \mathrm{~s}^{-1}$, and daytime average of $3.9 \mathrm{~mm} \mathrm{~s}^{-1}$ ) is completely damped during the restratifying night hours. We observed internal waves in the thermocline below the convective mixed layer with intriguing variations between night and day. Maximum of internal wave energy was found to start in the afternoon and continue long after the end of solar radiation forcing. Our analysis indicates that local convective processes are key forcing mechanisms for the generation of internal waves in ice-covered lakes. We also hypothesize that spatial differential heating between the nearshore regions and the centre of the bay (e.g. density current intruding the thermocline) could be a source of internal waves in ice-covered lakes.

Keywords Ice-covered lake $\cdot$ Solar radiation · Radiative heating - Convective mixed layer · Underice convection $\cdot$ Internal waves

\section{Introduction}

Ice-covered lakes are topped by cold surface layers with temperatures below $4^{\circ} \mathrm{C}$. Due to the ice cover, these layers are protected from wind stress and exposed to only weak solar radiation (Farmer, 1975; Matthews \& Heaney, 1987). In these extremely 
quiescent and low temperature environments, biogeochemical and physical processes have got little attention in freshwater research. Recent evidences of the role of inland waters for the global carbon cycle (Cole et al., 2007) led to a renewed interest in winter limnology in the context of climate change (Tranvik et al., 2009). In boreal, arctic and alpine regions, carbon and methane fluxes during ice-covered periods, for instance, are still merely taken into account (Karlsson et al., 2013). Winter limnology not only requires specific biogeochemical investigations but also dedicated hydrodynamic studies as the physics is quite different from that during ice-free periods.

Mironov et al. (2002) and Jonas et al. (2003b) quantified the importance of radiatively driven convection in ice-covered lakes. This phenomenon can be observed in nearly any ice-covered freshwater body as soon as snow covers disappear. Unhindered by snow, the solar radiation penetrates through ice and warms the underlying cold-below $4^{\circ} \mathrm{C}$-water. When the solar warming during day is stronger than the cooling at night, the net temperature increase causes convective thermals to form. Depending on the spring weather, these conditions are usually reached in boreal lakes in March/April and last for several weeks until the lake surface approaches $4^{\circ} \mathrm{C}$. If waters are shallow, the phenomenon may last for only two to 4 weeks, as shown by Malm et al. (1998) and Zdorovennov et al. (2013) for Lake Vendyurskoe or it may last for 2 months as in deep Lake Baikal (Schmid et al., 2007). In the Fig. 8 of the latter study, it was well documented that radiatively induced convection first occurs for the month of April under ice and then for the entire May in the open water until $4^{\circ} \mathrm{C}$ at the surface initiates the summer stratification.

Under-ice convection can trigger early growth of phytoplankton (Vehmaa \& Salonen, 2009), as convective thermals mix deeper-laying nutrients close to the ice cover. Vertical velocities associated with thermal plumes are thought to overcome the settling velocity of non-motile phytoplankton and to keep it close to the nutrients in the light-flushed layer situated just below the ice (Kelley, 1997). Today, the challenge in winter limnology remains interdisciplinary and, for instance, the exact role of under-ice convection for the early phytoplankton growth remains to be quantified (Kelley, 1997; Hampton et al., 2015).

Besides the importance of quantifying the under-ice convection as driver for early growth under ice, the role of the convection in the entire water column remains to be investigated. Of particular interest is also the potential role of solar radiation in energizing the thermally inversely stratified zone below the convectively mixed layer (CML), which we call "thermocline" in this article. Energy input to this thermocline will result in an increase of the vertical flux, thereby promoting oxygen transfer to the deep layers (Bouffard et al., 2013), upward fluxes of nutrients to the photic zone (Ostrovsky et al., 1996), or upward flux of $\mathrm{CO}_{2}$ and $\mathrm{CH}_{4}$ from the near bottom layer (Karlsson et al., 2013). Observations typically show internal wave activities in the winter thermocline that cannot be linked directly to wind forcing as is the case for open waters (Bouffard \& Boegman, 2012). In ice-covered lakes, barotropic oscillations are generated by oscillations of the ice cover resulting from changes in atmospheric pressure and wind forcing (Bengtsson, 1996). Kirillin et al. (2009) observed baroclinic basin-scale internal waves (e.g. Poincaré waves and Kelvin waves), and identified the forcing of these waves as a release of potential energy after lake freezing on the thermocline slope. Alternatively, laboratory and modelling activities have shown the potential for convective flow to initiate internal wave activities (Turner, 1973) through two different mechanisms. The first is associated with convective plume directly impinging the thermocline. Townsend (1964) used a tank with cold $\left(<4^{\circ} \mathrm{C}\right)$ stably stratified freshwater heated from the top to demonstrate how convective plumes generate internal waves as they impinge onto the stable layer. Recently, Ansong and Sutherland (2010) showed that $4 \%$ of the convective plume energy can be transferred to the internal wave field. The second is associated with nearshore density currents flowing along the slope before intruding the thermocline and generating progressive internal waves due to deflections caused by the fluid intrusion (Maxworthy et al., 2002; Flynn \& Sutherland, 2004; Nash \& Moum, 2005).

Although the physical drivers of under-ice convection are largely understood (Farmer, 1975; Matthews \& Heaney, 1987; Mironov et al., 2002), the dynamics of the under-ice water column associated with solar radiation forcing is still to be clarified. This research is a first piece of an international interdisciplinary research program aiming at quantifying life under ice in deep, large lakes. In this paper, we focus on quantifying the under-ice convection and investigating its role in the 
generation of internal waves along the winter thermocline in a side bay of Lake Onega.

\section{Methods}

Under-ice field measurements

Measurements were carried out in the central part of the Petrozavodsk Bay (PB) of Lake Onega (Russia) from March 14 to March 25, 2015. PB is located in the western part of the lake; the surface area of $\mathrm{PB}$ stretches along a southwest-northeast axis (Fig. 1A, B). The length and width of PB are, respectively, 10 and $5 \mathrm{~km}$ with a mean depth of $15 \mathrm{~m}$. The deepest trench follows the main axis of $\mathrm{PB}$ and reaches $30 \mathrm{~m}$ at the outlet. An inflow (Lake Logmozero and River Shuya) enters PB at its northern end.

We deployed the two-week base camp $\sim 2 \mathrm{~km}$ from the shore at $\mathrm{N} 61^{\circ} 48,744^{\prime} / \mathrm{E} 34^{\circ} 25,793^{\prime}$ in the middle of $\mathrm{PB}$, where the water is $27 \mathrm{~m}$ deep. The under-ice measurements included (i) a mooring lasting for 10-days and (ii) round-the-clock vertical profiles. We used the following instruments (Fig. 1C; Table 1): 1 meteorological station, 3 pyranometers, 22 temperature loggers, 9 photosynthetically active range (PAR) sensors, $1 \mathrm{CTD}$, and 1 temperature microstructure profiler. A dedicated hole was prepared for each instrument. Each hole was separated enough from the others to minimize disturbances from parallel activities.
Fig. 1 A Petrozavodsk Bay bathymetry map with location of measurements station (white quadrangle), B Lake Onega, C Setup of the observational site in March 2015, sketch of the thermal structure in underice convection and of the radiative transfer through the ice. Symbols are described in the "Methods" section

\section{A}
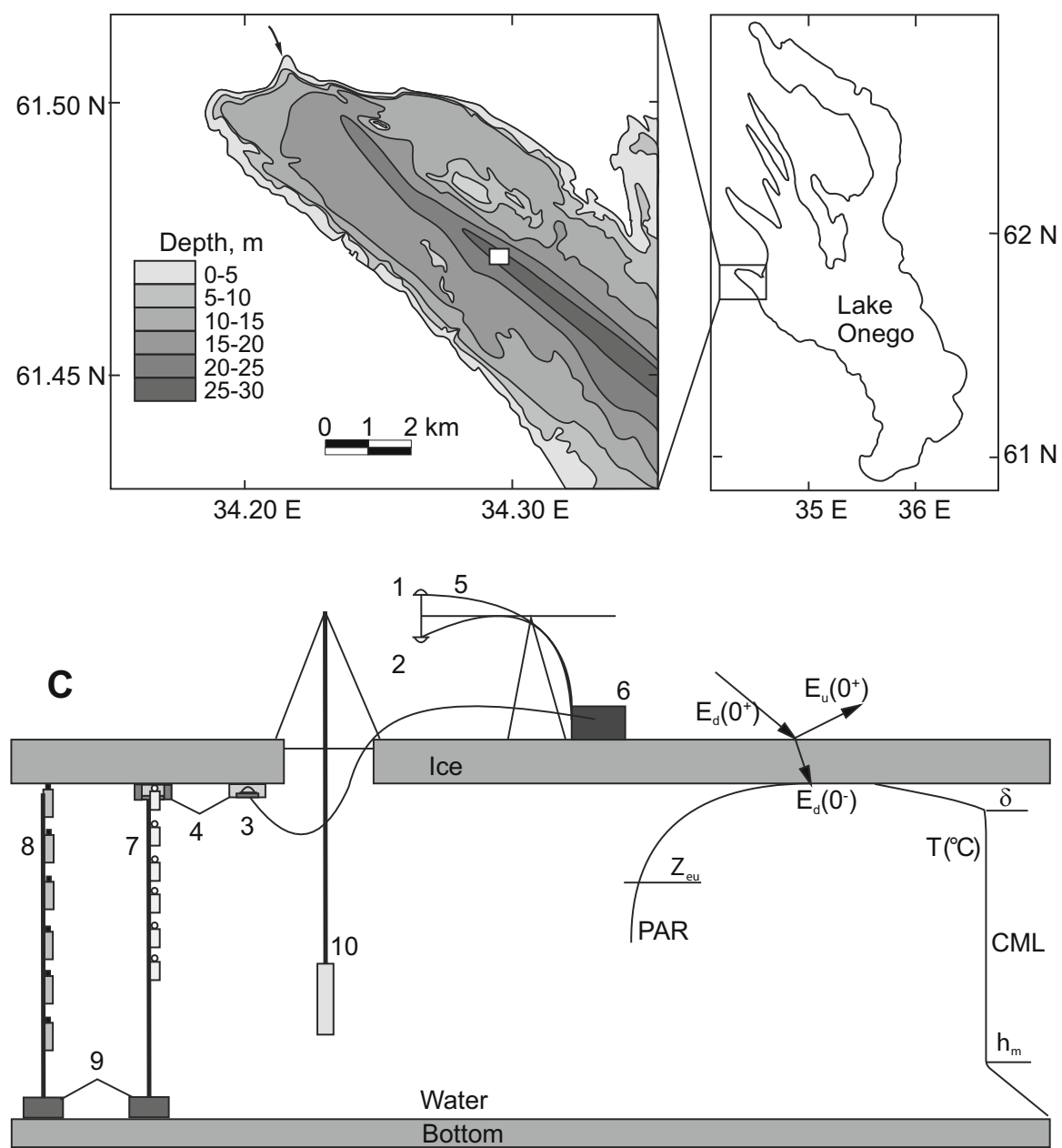

Radiation station:1-3 - pyranometers; 4 - foam plates; 5 - cable; 6 - laptop; 7 - PAR-chain; 8 - TR-chain, 9 - anchors; 10 - Profile station (CTD-90M, SCAMP) 
Table 1 Equipment used in the field campaign

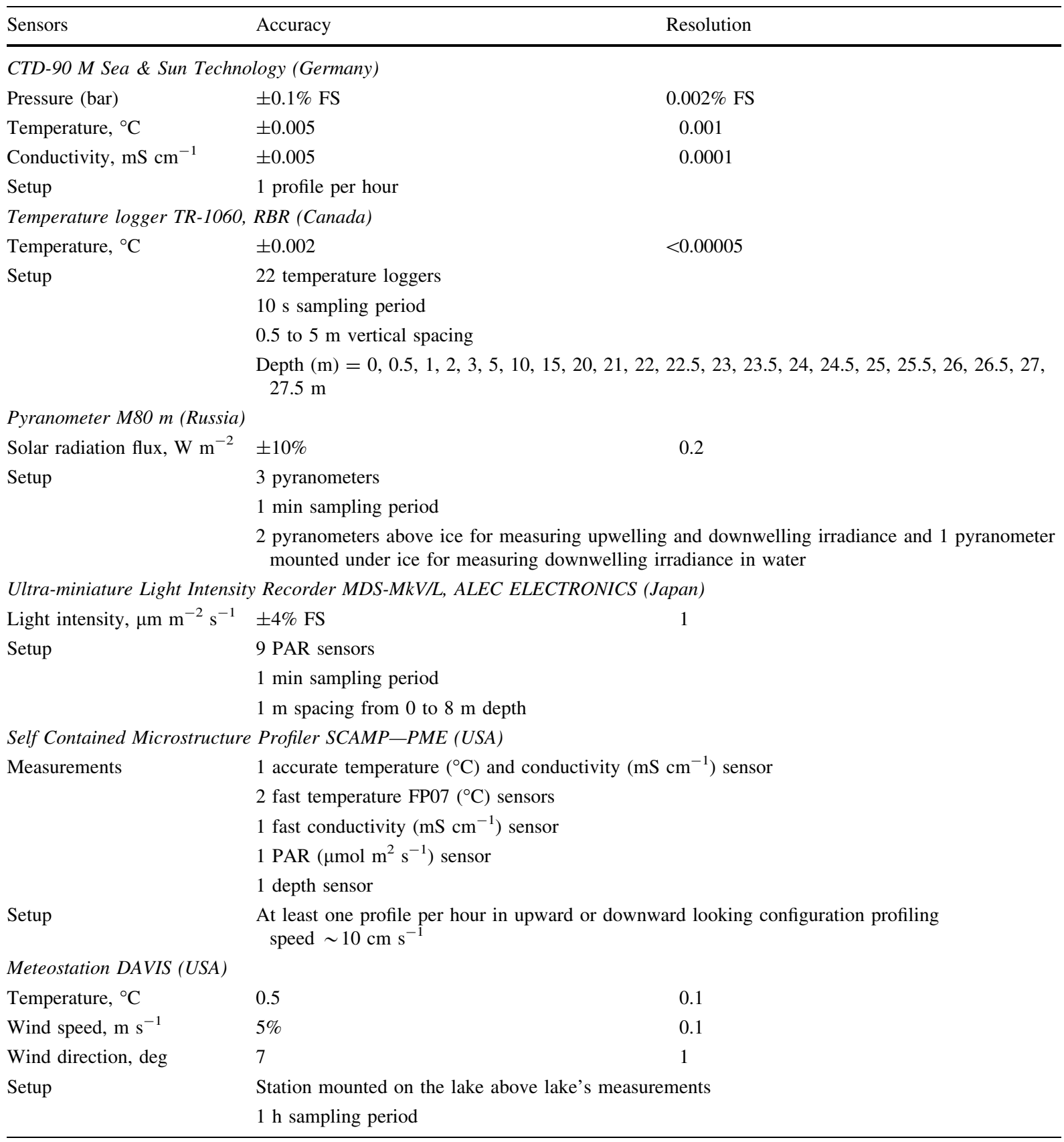

Solar radiation

The main external forcing in ice-covered lakes is the solar radiation, with albedo, transmittance and attenuation coefficient being three parameters controlling the radiative energy deposition in the water column. Albedo

$$
\alpha=\frac{E_{\mathrm{u}}\left(0^{+}\right)}{E_{\mathrm{d}}\left(0^{+}\right)},
$$

is calculated as the ratio between upwelling, $E_{\mathrm{u}}\left(0^{+}\right)$, and downwelling, $E_{\mathrm{d}}\left(0^{+}\right)$, solar irradiance above the ice $\left(0^{+}\right.$, pyranometers 1 and 2 on Fig. 1C). Transmittance 
$\tau=\frac{E_{\mathrm{d}}\left(0^{-}\right)}{(1-\alpha) E_{\mathrm{d}}\left(0^{+}\right)}$,

is calculated as the ratio of transmitted, $(1-\alpha)$ $E_{\mathrm{d}}\left(0^{+}\right)$, to incident irradiance, $E_{\mathrm{d}}\left(0^{-}\right)$, where $0^{-}$ refers to the lower ice boundary.

Assuming a local exponential decay of PAR in the water column as a function of depth, we calculated the attenuation coefficient $K_{\mathrm{w}}$ between two depth $z_{1}$ and $z_{2}$ from the measured values of PAR at the lower surface of the ice cover and at different depths in the water column:

$K_{\mathrm{w}}\left(z_{2}, z_{1}\right)=-\frac{1}{z_{1}-z_{2}} \ln \left(\frac{E_{\mathrm{d}}\left(z_{1}\right)}{E_{\mathrm{d}}\left(z_{2}\right)}\right)$.

The euphotic depth, $Z_{\text {eu }}$, is the depth where $1 \%$ of the surface PAR remains. Further, we defined the end of daytime as the time, $T_{\mathrm{SR} \text {,end }}$ when solar radiation, $\mathrm{SR}$, drops below $5 \%$ of the previous maximum solar radiation. From this definition, sunset was defined as $6.30 \mathrm{pm}( \pm 12 \mathrm{~min})$ over the ten days of observation.

Scaling relations for convective mixing

We could not measure directly the convective velocity and used the scaling relation for convective turbulence described by Mironov et al. (2002)

$w_{\mathrm{c}}=\left(B h_{\mathrm{cml}}\right)^{1 / 3}$,

with $B\left(\mathrm{~m}^{2} \mathrm{~s}^{-3}\right)$ the buoyancy flux in the convective layer spent to keep the convective layer vertically mixed and $h_{\mathrm{cml}}$, the mixed layer thickness defined as the distance between the base of the diffusive under-ice layer $(\delta)$ and the bottom to the mixed layer $\left(h_{\mathrm{m}}\right), h_{\mathrm{cml}}=h_{m}-\delta$ (Fig. 1C). Both ends are determined based on CTD data with a criteria of $\mathrm{d} T / \mathrm{d} z<0.1^{\circ} \mathrm{C} \mathrm{m}^{-1}$. The buoyancy flux was estimated using

$$
\begin{aligned}
B= & g \alpha_{\mathrm{T}}(\delta) I(\delta)+g \alpha_{\mathrm{T}}\left(h_{\mathrm{m}}\right) I\left(h_{\mathrm{m}}\right) \\
& -2\left(h_{\mathrm{m}}-\delta\right)^{-1} \int_{\delta}^{h_{\mathrm{m}}} g \alpha_{\mathrm{T}}(z) I(z) \mathrm{d} z,
\end{aligned}
$$

and, $I\left(\mathrm{~K} \mathrm{~m} \mathrm{~s}^{-1}\right)$ the kinematic radiation flux

$I(z)=\frac{E_{\mathrm{d}}(z)}{\rho_{0} c_{p}}$,

with, $g$, the acceleration of gravity, $\alpha_{\mathrm{T}}$ the thermal expansion coefficient, $\rho_{0}$ a reference density of water, $c_{p}=4.2 \times 10^{3} \mathrm{~J} \mathrm{~kg}^{-1} \mathrm{~K}^{-1}$ the specific heat of water at constant pressure.
We also estimated the buoyancy flux in the shearfree convective layer by assuming steady-state conditions in the turbulent kinetic energy (TKE) budget (Wüest \& Lorke, 2003)

$B=\frac{1}{c_{2} h_{\mathrm{cml}}} \int_{\delta}^{h_{\mathrm{m}}} \varepsilon(z) \mathrm{d} z$,

with $c_{2}$, a constant term accounting for other terms such as entrainment and divergence flux preventing a one-to-one ratio between energy production by buoyancy flux and energy dissipation $\left(\varepsilon, \mathrm{m}^{2} \mathrm{~s}^{-3}\right)$. Jonas et al. (2003b) calculated a ratio of 0.74 between $\varepsilon$ and $B$ in the under-ice convective layer in Lake Vendyurskoe. The rate of dissipation $\varepsilon$ of turbulent kinetic energy, was derived from temperature microstructure measurements (see below).

From the convective velocity, we estimated the convective energy, $E_{\text {conv }},\left(\mathrm{J} \mathrm{m}^{-2}\right)$ associated with the kinetic energy as

$E_{\text {conv }}=\frac{1}{2} \rho \int_{\delta}^{h_{\mathrm{m}}} w^{* 2} \mathrm{~d} z$.

Temperature microstructure measurements

The rate of dissipation $\varepsilon$ of turbulent kinetic energy was estimated using temperature fluctuation profiles measured by a Self Contained Autonomous Microstructure Profiler (SCAMP). We followed here the method used by Bouffard et al. (2012), and Bouffard \& Boegman (2013), which consists in fitting the high frequency $(100 \mathrm{~Hz})$ temperature fluctuations to the Batchelor spectrum. We waited at least $20 \mathrm{~min}$ (mostly $\sim 60 \mathrm{~min}$ ) between two profiles to insure the artificially generated turbulence from the previous drop to be fully dissipated. Ideally, under-ice microstructure profiles should be carried out in upward looking mode to estimate dissipation up to a few centimetres below the ice but the deep location of the thermocline close to the bottom was also of interest and we decided to conduct both upward and downward microstructure profiles. Results are provided in Annex 1 in Supplementary material.

\section{Internal waves energy}

The internal wave activity (amplitude and energy) was analysed by calculating the internal wave energy, $E_{\mathrm{IW}}$ 
(Antenucci \& Imberger, 2003). $E_{\mathrm{IW}}$ is inferred from the available potential energy, APE, embedded in the bandpass filtered (300 s to $3600 \mathrm{~s}$, see results and discussion section for justification) wave-induced isotherm displacements $\left(d_{\mathrm{IW}}\right), E_{\mathrm{IW}}=2 \mathrm{APE}\left(\mathrm{J} \mathrm{m}^{-2}\right)$, the factor 2 accounting for the equipartition between potential and kinetic short internal waves energy (Gill, 1982). $E_{\mathrm{IW}}$ is defined as (Kang \& Fringer, 2010; Wüest \& Schmid, 2012),

$E_{\mathrm{IW}}(t)=2 \frac{\rho}{2 A_{\mathrm{S}}} \int N^{2}(z, t) d_{\mathrm{IW}}^{2}(z, t) A(z) \mathrm{d} z$

with $N\left(\mathrm{~s}^{-1}\right)$, the Brunt-Väisälä frequency calculated from the thermistor chain, $A(z)$ and $A_{\mathrm{S}}\left(\mathrm{m}^{2}\right)$ being the lake area at depth $z$ and surface. We assumed $A(z)=A_{\mathrm{S}}$, and defined the range of integration as the vertical layer where $N^{2}>5 \times 10^{-5} \mathrm{~s}^{-2}$. Equation 9 is not sensitive to the bounds of integration, as $N^{2}$ is at least two orders of magnitudes larger in the thermocline than in the mixed layer above. Isotherm displacements extracted from the thermistor chain were band-pass filtered ( $5 \mathrm{~min}$ to $1 \mathrm{~h}$ ) to only represent the investigated internal wave oscillations.

\section{Results}

Meteorological conditions during measurements

Measurements in March 2015 were performed under two different meteorological forcing conditions (Fig. 2A). The first 5 days were mild with positive air temperatures during daytime and almost no wind. The following 5 days were characterized by a severe drop in temperature (down to $-10^{\circ} \mathrm{C}$ ) and persistent strong wind reaching $10 \mathrm{~m} \mathrm{~s}^{-1}$. On March 14-17, the sky was clear; on March 18-19, 22 and 25 the cloud cover reached 30-80\% and on March 20-21 it reached 60-100\%; on 23-24 March, the sky was almost constantly overcast. It snowed during the nights of March 20-21 and 23-24.

Solar radiation and ice optical properties

The difference between the two weeks of field measurements is also noticeable in the time series of the solar radiation (Fig. 2B). The first 5-days (March 15-19) are characterized by an almost clear sky and solar radiation close to its seasonal astronomical maximum for this latitude. The time series over the second 5-days (March 20-24) show that the solar radiation is more scattered and its intensity is up to two times less than during the first period. Differences between the two periods are provided in Table 2.

The averaged midday (between $11 \mathrm{am}$ and $3 \mathrm{pm}$ ) albedo was 0.15 (standard deviation, STD of \pm 0.02 ) during the first period and increased to $0.33 \pm 0.23$ during the second period (Fig. 2C; Table 2). This noticeable increase was associated with the change of weather and snowfall. The lake surface was essentially of non-uniform reflectivity because the wind redistributed snow on the ice surface. The ice was covered with patches of snow with a thickness of a few $\mathrm{cm}$ and up to several $\mathrm{dm}$ in diameter. Typically, the highest values of albedo were observed in the morning, whereas albedo was reduced over the day with surface ice melting except on March 20 and 23. The daytime albedo variability is responsible for the elevated measured STD. The sharp increase in albedo up to 0.9 on March 24 was due to the fallout of dry snow that formed a continuous layer of a few mm thickness on the surface of the ice. However, the thin layer of snow was quickly blown by the wind or partially melted, and on the following day the albedo dropped to 0.2. The averaged value of 0.18 was low, which is characteristic of clear ice with little or no snow.

The thickness of the ice layer at the beginning of the measurements reached $39 \mathrm{~cm}$, and only decreased by $1 \mathrm{~cm}$ over 10 days. Ice was clean, and contained a small amount of air bubbles.

The transmittance was increased slightly from March 14 to 22, with average $0.40 \pm 0.13$ (Fig. 2C). The transmittance also presented a daily pattern reducing to 0.2 in the afternoon. Presumably, this drop in light penetration was associated with the physical change of the ice during the day.

Solar radiation into the water

On March 15-19, the daily maxima of the PAR flux at the top of the water (at water-ice boundary) exceeded $1200 \mu \mathrm{mol}$ photons $\mathrm{m}^{-2} \mathrm{~s}^{-1}$, and reached $1500 \mu \mathrm{mol} \mathrm{m}{ }^{-2} \mathrm{~s}^{-1}$ on March 22 (Fig. 2D). The sharp decrease of the PAR flux in the under-ice layer on March 23 and 24 was caused by snowfall and an increase in albedo. The PAR flux decreased also rapidly with depth. Daily maxima of the PAR flux did not exceed 300 and $100 \mu \mathrm{mol} \mathrm{m} \mathrm{m}^{-2} \mathrm{~s}^{-1}$ at depth of 1 and 
Fig. 2 Meteorological data: A Air temperature and Wind speed measured at the field site (Fig. 1). B Time series of solar irradiation above $\left(E_{\mathrm{d}}\left(0^{+}\right), E_{\mathrm{u}}\left(0^{+}\right)\right)$and below ice $\left(E_{\mathrm{d}}(z)\right)$.

C Estimated albedo $(\alpha)$ and transmissivity $(\tau)$ for the period from 9 am to $6 \mathrm{pm}$ during March 2015. D Time series of PAR. E Time series of calculated $K_{\mathrm{w}}$ and $Z_{\mathrm{eu}}$. All values of the time series were presented as $10-\mathrm{min}$ averages
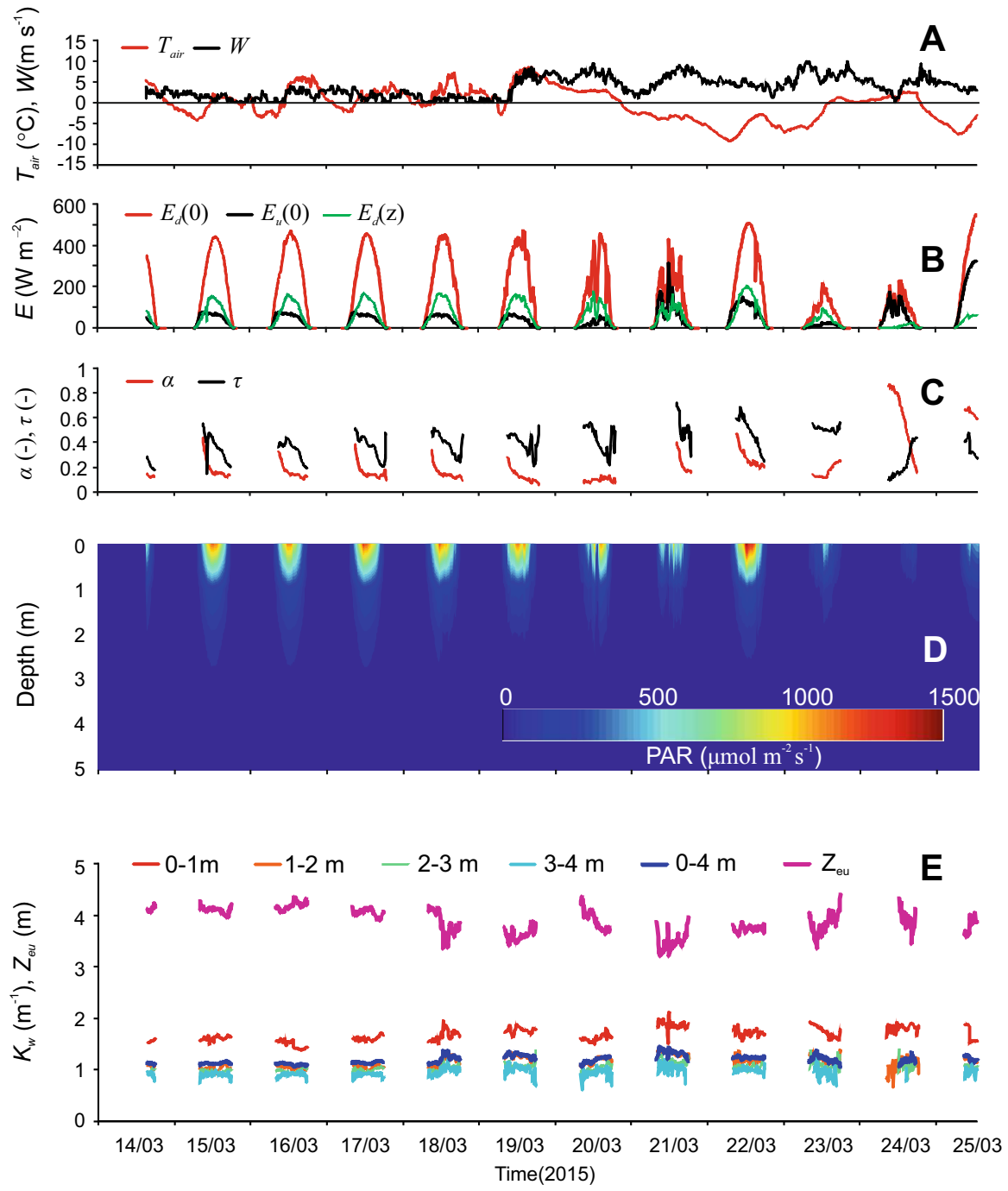

$2 \mathrm{~m}$ of depth, respectively. At $5 \mathrm{~m}$ depth, the PAR flux was below detection.

The maximal values of the PAR attenuation coefficient, $K_{\mathrm{w}}$, estimated by Eq. 3 were confined to the under-ice layer of $0-1 \mathrm{~m}$ and varied between 1.5 and $2.1 \mathrm{~m}^{-1}$ (Fig. 2E). The values of $K_{w}$ slightly decreased with increasing depth and varied from 1.0 to $1.4 \mathrm{~m}^{-1}$ in layer $1-2 \mathrm{~m}, 0.9-1.3 \mathrm{~m}^{-1}$ in layer $2-3 \mathrm{~m}$, and $0.8-1.1 \mathrm{~m}^{-1}$ in layer $3-4 \mathrm{~m}$. The average $K_{\mathrm{w}}$ value for the layer $0-4 \mathrm{~m}$ ranged within $1-1.4 \mathrm{~m}^{-1}$. The depth of the euphotic zone estimated using averaged values of $K_{\mathrm{w}}$ was slightly greater and reached $4.3 \mathrm{~m}$ during the first measurement period, and decreased to $3.5 \mathrm{~m}$ during the second period. Such light attenuation values are low compared to surrounding lakes with coloured dissolved organic matter strongly damping the light.

The observed conditions with high SR, clear ice (low albedo and high transmittance) and moderate light attenuation are ideal for triggering radiatively driven under-ice convection.

Thermal structure and under-ice convection

The vertical structure of the water column under the ice is characterized by three layers (Fig. 1C) during the penetrative convection phase: (1) a thin under-ice gradient layer, (2) a convectively mixed layer (CML) and (3) a stably stratified quiescent layer underneath (Kirillin et al., 2012). The under-ice gradient layer (1) 
Table 2 Averaged meteorological properties for the measurements

\begin{tabular}{lcr}
\hline & Period 1 & Period 2 \\
& $15-19$ March 2015 & Match 2015 \\
\hline Tair $\left({ }^{\circ} \mathrm{C}\right)$ & $1.54(3.02)$ & $-1.95(3.54)$ \\
Wind speed $\left(\mathrm{m} \mathrm{s}^{-1}\right)$ & $1.93(1.81)$ & $5.35(1.91)$ \\
$\mathrm{E}_{\mathrm{d}}\left(0^{+}\right)\left(\mathrm{W} \mathrm{m}^{-2}\right)$ & $333(102)$ & $214(138)$ \\
$\mathrm{E}_{\mathrm{u}}\left(0^{+}\right)\left(\mathrm{W} \mathrm{m}^{-2}\right)$ & $52(18)$ & $57(47)$ \\
$\mathrm{E}_{\mathrm{d}}\left(0^{-}\right)\left(\mathrm{W} \mathrm{m}^{-2}\right)$ & $106(43)$ & $71(55)$ \\
$\alpha$ & $0.15(0.02)$ & $0.33(0.23)$ \\
$\tau$ & $0.40(0.04)$ & $0.43(0.16)$ \\
$K_{w}\left(\mathrm{~m}^{-1}\right)$ & $1.17(0.09)$ & $1.24(0.07)$ \\
$\mathrm{Z}_{\mathrm{eu}}(\mathrm{m})$ & $3.93(0.28)$ & $3.73(0.2)$ \\
\hline
\end{tabular}

Given the change in weather conditions, two periods of five days are considered. Air temperature and wind speed are daily averaged. $E_{\mathrm{d}}(0), E_{\mathrm{u}}(0), E_{\mathrm{d}}(\mathrm{z})$ are averaged from 9 am to $6 \mathrm{pm}$. Albedo, transmissivity, attenuation coefficient and euphotic depth are averaged from 11 am to $3 \mathrm{pm}$. In brackets-standard deviation

was clearly recognizable during the measurements, as its temperature gradient periodically reached $1.5^{\circ} \mathrm{C} \mathrm{m}^{-1}$ (Fig. 3). The upper boundary of the CML was observed at $0.2-0.6 \mathrm{~m}$ from the ice and extended as deep as $\sim 20 \mathrm{~m}$. Daily solar radiation (Fig. 2B) imposed a volumetric heating of below $4^{\circ} \mathrm{C}$ thereby inducing convection. We observed every day a cycle between a mixed layer at daytime (convection) and a stable stratification with temperature increasing with depth at night (restratification).

We recorded a large day-to-day variation in the thickness of the CML (Fig. 3), by comparing the last CTD profile taken during daytime (e.g. 6 pm). At this time of the day, convection is still dominating restratification. The depth of the CML typically

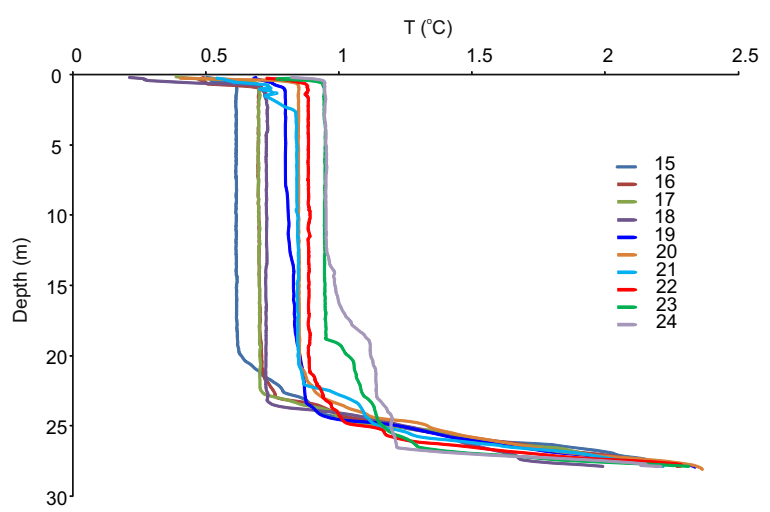

Fig. 3 Vertical profiles of water temperature at 18:00 from March 15 to 24, 2015. Numbers in the legend refer to the day in March 2015 extended down to $\sim 20-22 \mathrm{~m}$ over this period but was reduced to $18.5 \mathrm{~m}$ on March 23 (6 pm) and to $12.1 \mathrm{~m}$ on March 24 (6 pm). This substantial drop in the CML is related to the weaker SR in the second week (Fig. 2). Data from March 19 (6 pm) indicate a very weak temperature gradient in the CML below $7.5 \mathrm{~m}$. Such restratification is unexpected given the strong SR. Apparently, a substantial advective transport took place in the lower stratified layer on March 19 and again on March 23 and 24. Its influence extended to a depth of $10 \mathrm{~m}$. Such a large-scale horizontal transfer could be a manifestation of the large-scale dynamics between the PB and adjacent waters of Lake Onega, or nearby river outflow. Unfortunately, the lack of direct measurements of currents prevents to confirm this assumption.

The temperature of the CML increased to $0.04^{\circ} \mathrm{C} \mathrm{day}^{-1}$ over the nine days of measurements in the CML (Fig. 3) due to daytime radiation heating and redistribution of heat by convective mixing within the CML (Farmer, 1975; Mironov et al., 2002). This absolute temperature increase from 0.61 to $0.95^{\circ} \mathrm{C}$ was not constant over time (Fig. 4A). The temperature increase was strongly limited to days with comparatively weaker solar radiation (e.g. March 20, 23 and 24, Fig. 2). Over the period of measurements we estimate an average deepening rate of $0.3 \mathrm{~m} \mathrm{day}^{-1}$ but our measurements took place, while the convection was already setup and deep. Previous observations on boreal lakes suggested higher deepening rate of CML, higher CML and 
Fig. 4 Contour plot of A temperature over the entire water column, and B above the bottom for 20 March. C Power spectra of the $1.6^{\circ} \mathrm{C}$ isotherm over the 10 days period in March 2015. The cascade of energy has a spectral slope of -1.9 from $5 \mathrm{~min}$ to $2 \mathrm{~h}$ and -3.5 from $50 \mathrm{~s}$ to $5 \mathrm{~min}$, close to the very first marine observations by Wunsch (1972). White dots in A indicate location of the temperature loggers
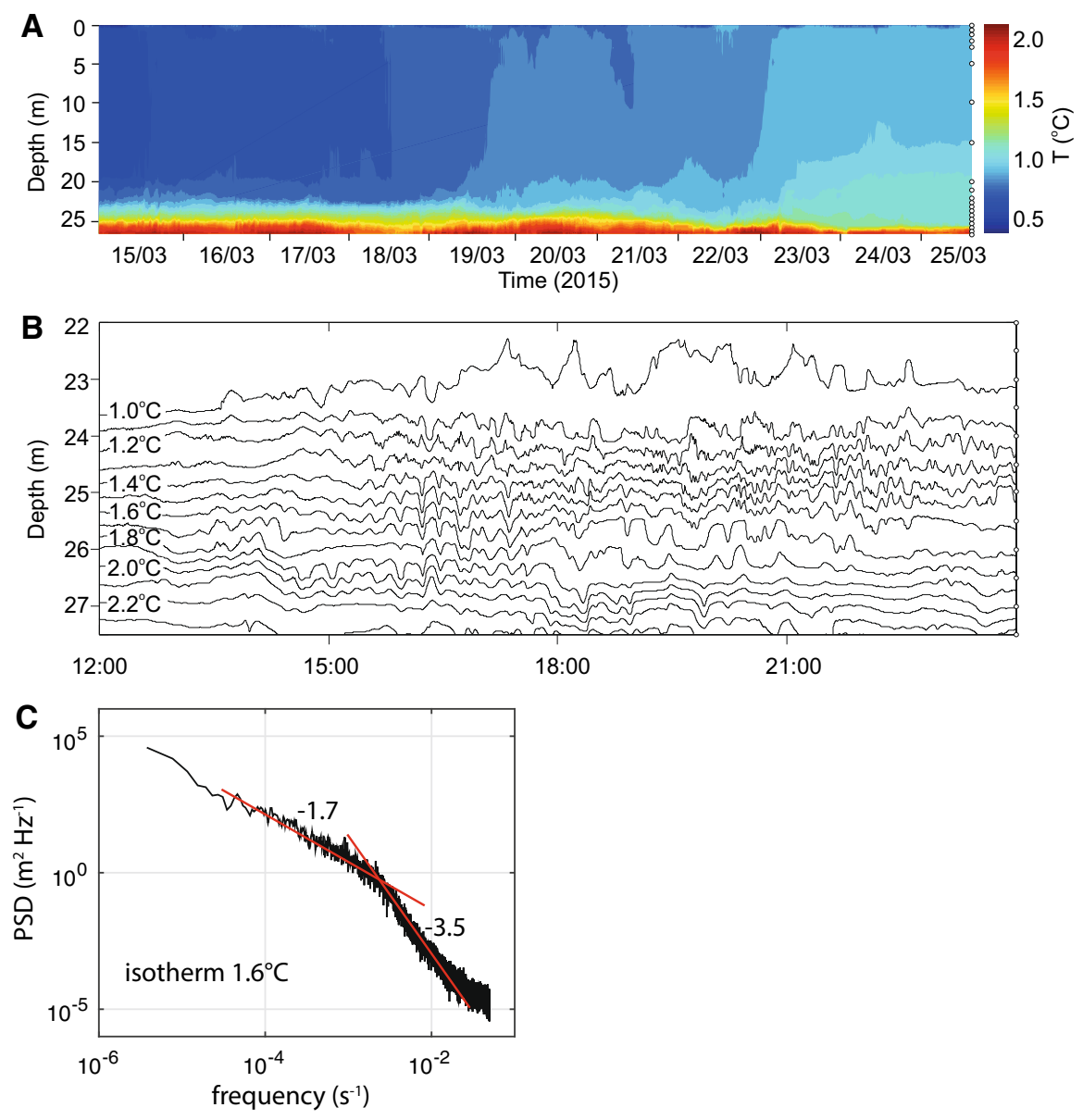

lower CML temperature in deep lakes as compared to shallow basins. For example, in deep-water Lake Pääjärvi (max depth $85 \mathrm{~m}$ ) deepening of the lower boundary of CML was observed to reach up to $3 \mathrm{~m} \mathrm{day}^{-1}$ (Kirillin et al., 2012), and convection could reach the whole water column, with CML temperature lower than $3^{\circ} \mathrm{C}$ (Salonen et al., 2014). In contrast, in the shallow Lake Vendyurskoe (max depth $13.5 \mathrm{~m}$ ) convection reaches only 7-9 $\mathrm{m}$, and the temperature of the CML was warmer than $3^{\circ} \mathrm{C}$ (Zdorovennov et al., 2013). The reason for such considerably different regimes of convection in deep and shallow ice-covered lakes is a remarkable difference between the vertical distributions of water temperature before the onset of radiatively driven convection. In shallow lakes, temperature profiles are characterized by a gradual increase from $0^{\circ} \mathrm{C}$ at the water-ice boundary to $\sim 4^{\circ} \mathrm{C}$ at the bottom (Petrov et al., 2006; Kirillin et al., 2012), and the average temperature gradient in the upper part of a water column can reach 0.3 to $0.4^{\circ} \mathrm{C} \mathrm{m}^{-1}$ before the onset of convection. Alternatively, in deep lakes, temperature gradient at the top of the water column merely exceeded $0.01{ }^{\circ} \mathrm{C} \mathrm{m}^{-1}$, and the region characterized by a slight increase of water temperature due to solar radiation penetrated into water effectively forms the CML with rates $1 \mathrm{~m} \mathrm{day}^{-1}$ or more (Schmid et al., 2007 in Baikal). Below the CML, we observed a thermocline with a stratification of $N^{2} \approx 10^{-5} \mathrm{~s}^{-2}$. This layer supported internal wave activity (Fig. 4B).

\section{Internal waves}

The stratified layer below the CML is prone to internal wave activity (Fig. 4A, B). We observed oscillations over a broad frequency range, and spectral analysis of isotherm displacement does not show any significant peaks during the ten days period 
(Fig. 4C). We instead observe a continuum of internal waves with periods from $\sim 50 \mathrm{~s}$ to $\sim 2 \mathrm{~h}$ with no preferential internal wave period excited. Given the stratification and the size of the PB, we estimated the longitudinal and transversal mode with the Merian equation (Bouffard \& Boegman, 2012), $T_{\text {long }} \sim 100 \mathrm{~h}$ and $T_{\text {lat }} \sim 50 \mathrm{~h}$. Note that both longitudinal and transversal wave period are too long to be well resolved over ten days of observation. The most intriguing feature is the daily pattern of the short-period $(<2 \mathrm{~h})$ internal wave activity. The isotherm displacements, as shown in Fig. 4B, indicated quiescent conditions in the morning followed by an increase in the wave amplitude of up to $1.5 \mathrm{~m}$ at the top of the thermocline (but $0.6 \mathrm{~m}$ in the thermocline) in the afternoon until around midnight.

The time series of the $1.6^{\circ} \mathrm{C}$ isotherm (Fig. 5A) located in the thermocline is used to characterize the internal wave field. We applied a wavelet analysis to investigate the temporal trend in the observed oscillations (Fig. 5B). The wavelet analysis highlights two different internal waves pattern. At long period $(>2 \mathrm{~h}$ ), the level of energy remains constant over time but for shorter wave period, we noticed a strong daily cycle in the wave energy. For periods between 5 min (typical lower range given by the $95 \%$ confidence interval of the wavelet analysis, not shown) and $2 \mathrm{~h}$, the power spectral density is higher from midday to midnight compared to the rest of the day. The time series of band averaged ( $5 \mathrm{~min}$ to $2 \mathrm{~h}$ ) power spectral density clearly shows the daily pattern in the short-period internal wave activity (Fig. 5C). The time series of by band-pass filtered isotherm displacement over the range $5 \mathrm{~min}$ to $2 \mathrm{~h}$ also shows a daily variation in the signal with displacement reaching up $0.6 \mathrm{~m}$ in the second part of the day (Fig. 5D).

The daily structure of the short-period internal waves with weak oscillations in the morning and maximum oscillations from midday to midnight calls for the SR as a trigger. The internal wave energy, $E_{\mathrm{IW}}$, embedded in the range $5 \mathrm{~min}$ to $2 \mathrm{~h}$ is calculated using Eq. 9. Not surprisingly, the time series of normalized $E_{\mathrm{IW}}$ (Fig. 6) has a very similar daily pattern to the time series of the power spectral energy of the isotherm displacements shown in Fig. 5D and is systematically offset with the daily oscillations of the normalized kinematic radiation flux, $I$ (Fig. 6).

\section{Discussion}

Under-ice convection

The potential of the convective turbulence to maintain non-motile phytoplankton in the lake surface layer depends on the upward velocity and the lifetime of the thermals. The convective velocity (Fig. 7A) estimated from the SR-based method never exceeded $7.4 \mathrm{~mm} \mathrm{~s}^{-1}$. The average maximum daily value was $\sim 3.9 \mathrm{~mm} \mathrm{~s}^{-1}$. Sander et al. (2000) showed by means of large eddy simulation (LES) and field measurements that in natural convection updraught area represents $40-60 \%$ of the convective area. Similarly, Jonas et al. (2003a) did not observe significant differences between upward and downward velocity in the CML. Mironov et al. (2001) suggested with LES data that downdraught areas are more localized that updraught areas leading allows net vertical transport of non-motile plankton. This convective velocity can therefore be used as a first-order proxy for the upward velocity.

We compared the SR-based method (Eqs. 4, 5 and 6) with the dissipation-based method (Eqs. 4 and 7) for the period March 20-21 (Fig. 7B). There is a very good agreement during daytime but the slow decay in the convective velocity cannot be seen from the first method based on solar radiation in which, by definition, the convective velocity is stopped at sunset. The dissipation-based method indicates that the convective velocity becomes negligible around $11 \mathrm{pm}$, i.e. $4.5 \mathrm{~h}$ after sunset or $9 \mathrm{~h}$ after the peak in solar radiation. Nieuwstadt \& Brost (1986) investigated the decay of convective turbulence by means of large eddy simulation in the case of a sudden drop of the forcing. They suggested that the decay time scales with the thickness of CBL and the upward convective velocity: $h_{\mathrm{cml}} / w_{\mathrm{c}}$. Sorbjan (1997) and Cole \& Fernando (1998) investigated the decay of convective turbulence in the more realistic case of a longer time decay of the forcing and found that its duration can exceed the decay time suggested by Nieuwstadt \& Brost (1986). For the period of March 20-21, the Nieuwstadt \& Brost (1986) parameterization suggests a decay time of $\sim 2 \mathrm{~h}$ after the end of the forcing immediately after the peak in SR at $3 \mathrm{pm}\left(t=T_{\mathrm{SR}}\right.$, peak $)$. This decay time is much shorter than the duration of the decaying forcing (e.g. $3.5 \mathrm{~h}$ when considering the 
Fig. 5 A Time series of the $1.6^{\circ} \mathrm{C}$ isotherm displacement located in the thermocline (Fig. 4A).

B Wavelet analysis of the $1.6^{\circ} \mathrm{C}$ isotherm displacement. White dotted line represents the upper $(2 \mathrm{~h})$ and lower period (5 min) of internal waves showing a daily variability. C Time series of bandaveraged (over the upper and lower limits defined above) power spectral density of the $1.6^{\circ} \mathrm{C}$ isotherm displacement. D Time series of the bandpass filtered ( $5 \mathrm{~min}$ to $2 \mathrm{~h}$ ) $1.6^{\circ} \mathrm{C}$ isotherm displacement
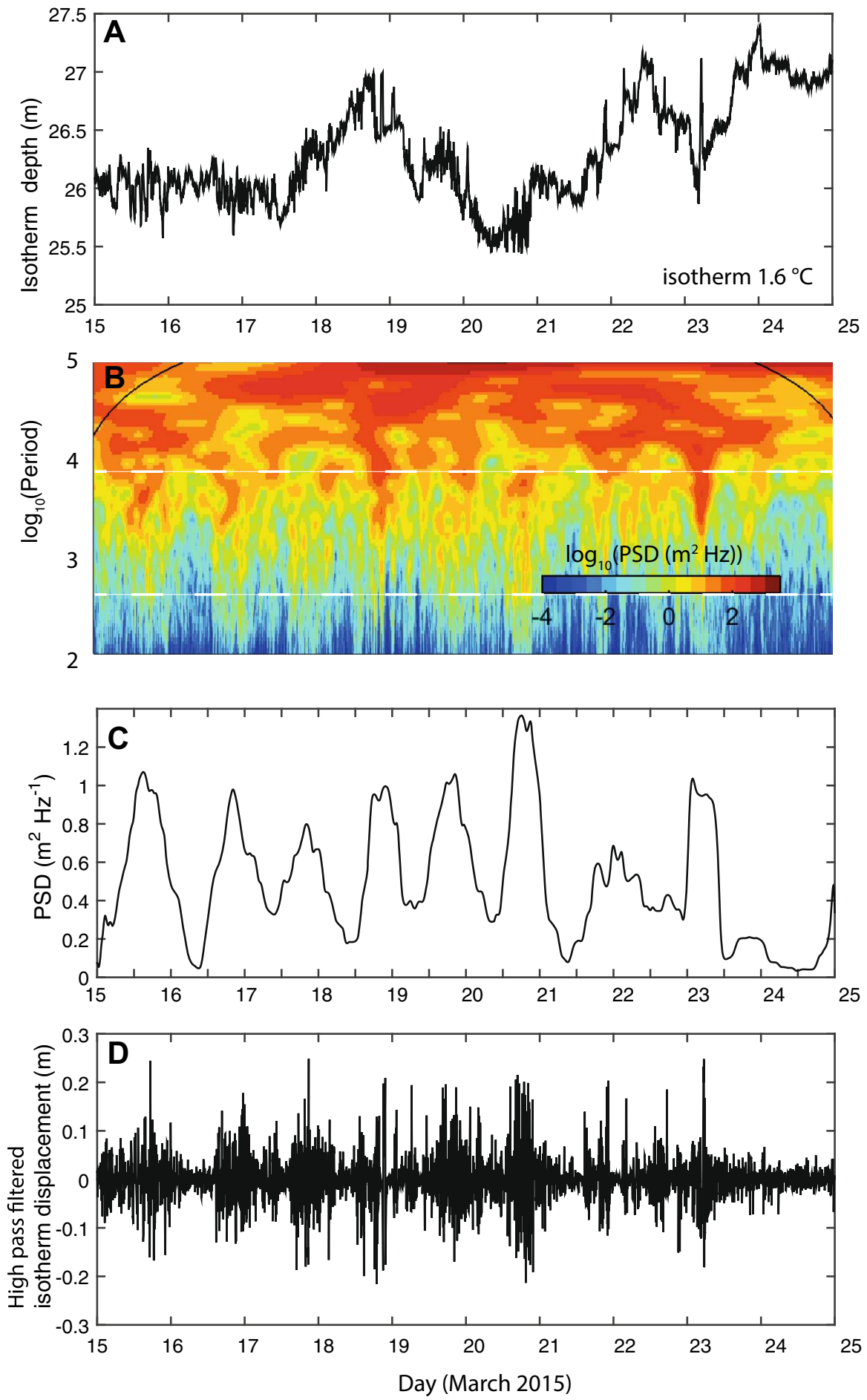

end of the SR forcing at $6.30 \mathrm{pm}$ and the SR peak at $3 \mathrm{pm}$ ). Kinetic energy of the convective velocity associated with the peak of energy input at $3 \mathrm{pm}$ has been dissipated before sunset. Similarly, the decay time calculated based on condition just before sunset (e.g. at $\mathrm{T}_{\mathrm{SR}}$, end $=6.30 \mathrm{pm}$ ) implies that the convective velocity will decrease until $10 \mathrm{pm}\left(h_{\mathrm{cml}} /\right.$ $w_{\mathrm{c}}=3 \mathrm{~h} 30 \mathrm{~min}$ ) which is in good agreement with 
Fig. 6 Time series of normalized kinematic radiation flux at $\mathrm{z}=\delta$ (under the ice) and internal wave energy. Max values set to 1

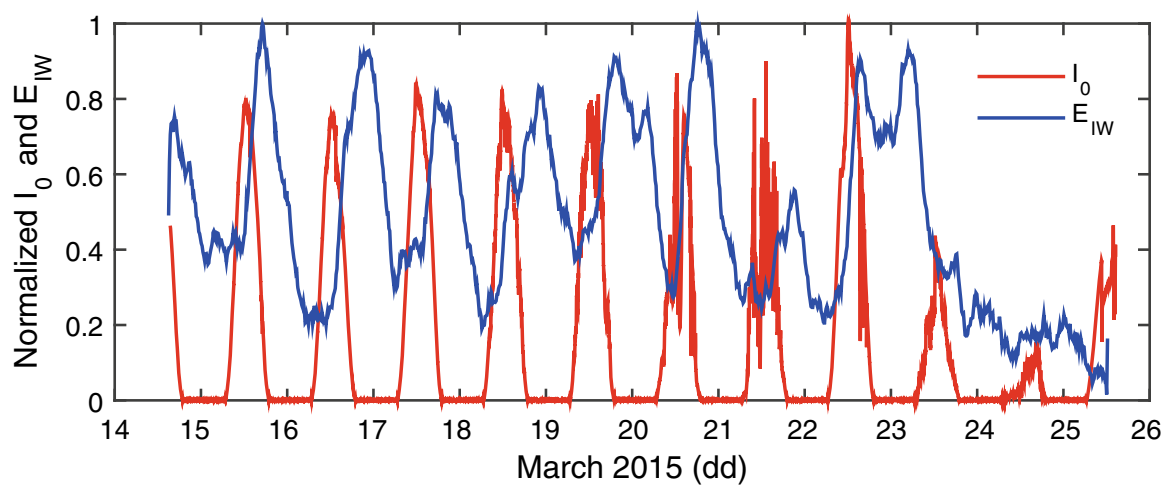

Fig. 7 A Estimated convective velocity over the 10-days of observation. B Comparison between the two methods (Eqs. 4, 5 and 6 for SR-based method and Eqs. 4 and 6 for dissipationbased method) over one period of $24 \mathrm{~h}$. $T_{\mathrm{SR} \text {, peak }}$ and $T_{\mathrm{SR} \text {, end }}$ are indicated with arrows on the figure
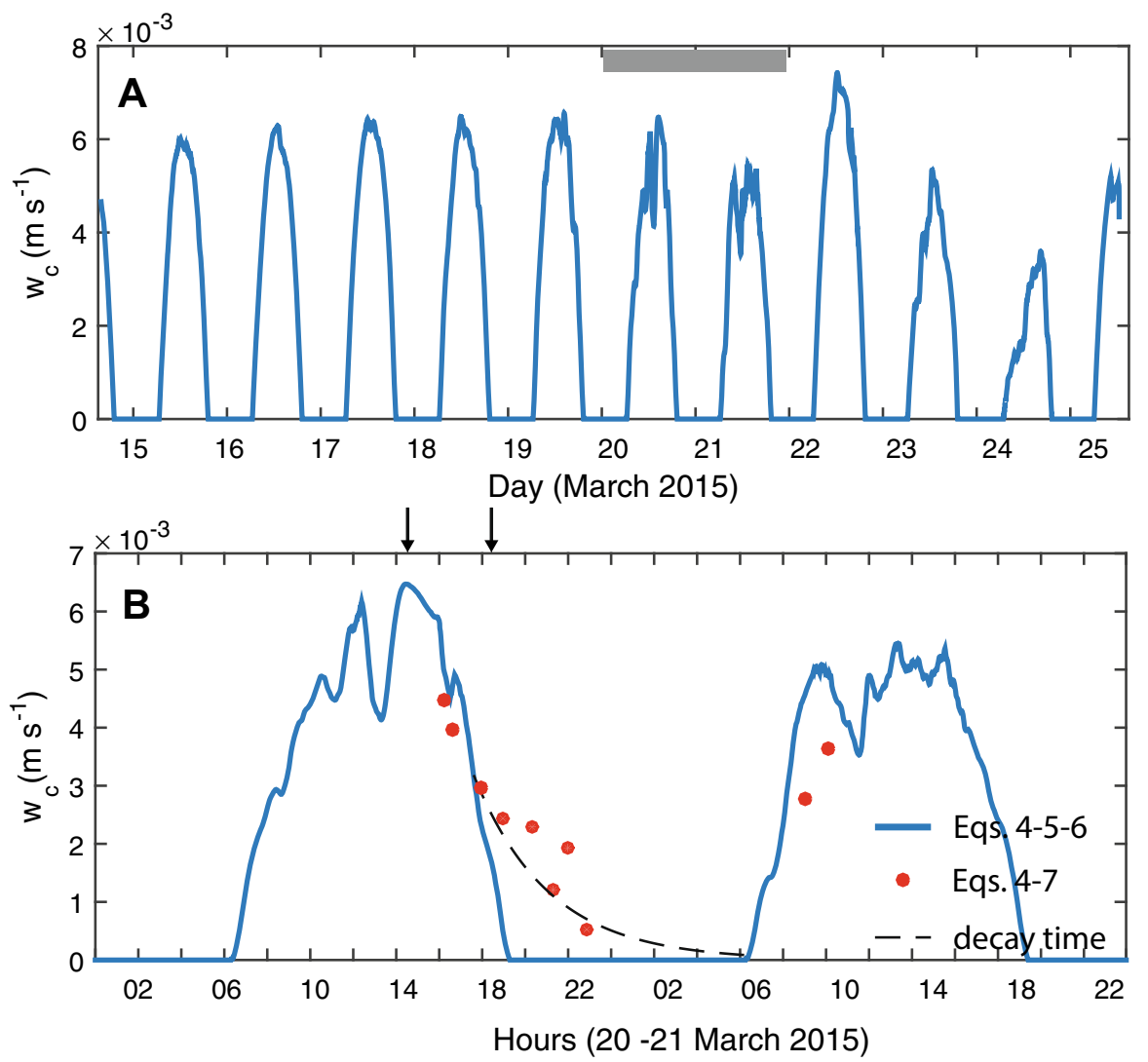

the dissipation-based estimate of the convective velocity (Fig. 7B). This is also shown by comparing the decay time scale from the parameterization of Nieuwstadt \& Brost (1986) to the e-folding time scale, of the convective velocity, as estimated from the dissipation-based method (e.g. exponential decay fitting of the data). We estimated here the e-folding time scale as $3 \mathrm{~h} 30 \mathrm{~min}$, i.e. $63 \%$ of the energy has been dissipated after this time.
The parameterization of Nieuwstadt \& Brost (1986), $h_{\mathrm{cml}} / w_{\mathrm{c}}$, seems a reasonable approximation of the decay time scale when the calculation is performed around $t=T_{\mathrm{SR}}$, end. We then corrected the SR-based method by adding a decay time to the previously calculated convective velocity. We have shown above that there was no need to take into account the convective velocity at $t=T_{\mathrm{SR}}$, peak, mostly because at this time the decay time is much 
shorter than the duration of the SR and all convective energy initiated at the SR peak time is already dissipated at dusk. We finally used the following correction: $w_{\mathrm{c}}\left(t>T_{\mathrm{SR}, \text { end }}\right)=w_{\mathrm{c}}\left(T_{\mathrm{SR}, \text { end }}\right)$ $e^{-t w^{*}\left(T_{\mathrm{SR}, \text { end }}\right) / h_{\mathrm{cml}}}$. This corrected SR-based convective velocity method (Fig. 7B) is in good agreement with the dissipation-based method. Other comparisons on days 23-24 and 25 March also indicate a good agreement between the two methods during daytime and during the evening when a decay time is applied to the SR-based method.

In summary, assuming an end of the SR forcing around $6.30 \mathrm{pm}$, an averaged CML thickness of $\sim 21 \mathrm{~m}$ and an average convective velocity of $3 \mathrm{~mm} \mathrm{~s}^{-1}$ (at $6 \mathrm{pm}$, Fig. 7B), we estimated that $63 \%$ of the kinetic energy from the convective plumes will be dissipated after $2 \mathrm{~h} 20 \mathrm{~min}$ and $86 \%$ after $3 \mathrm{~h}$ $45 \mathrm{~min}$ (e.g. 10:15 pm). Then, the restratification processes will become dominant.

\section{Internal wave activity}

The time series of the temperature loggers showed significant internal activity inside the stratified region underneath the CML (Figs. 4B, 5). Time series of isotherm displacements (Fig. 5) and internal wave energy (Fig. 6) indicate a daily structure. The intensity of the daily peak of internal wave activity is clearly linked to the intensity of the solar radiation (Fig. 8A) and more internal wave activity is expected on sunny days. However, we observed daily peaks in internal wave activity to occur between $6 \mathrm{pm}$ and $10 \mathrm{pm}$ or $8: 30 \mathrm{pm}$ on average, that is roughly $9 \mathrm{~h}$ after the peak in solar radiation occurs (Fig. 6). Given this daily cycling, we tentatively linked the supply of $E_{\mathrm{IW}}$ to the solar radiation. We discuss two processes that may explain this energy supply:
- H1 Direct energy input from convective plumes impinging the thermocline (Townsend, 1964; Stull, 1976; Ansong \& Sutherland, 2010).

- H2 Remote energy input from shoreline excess heat flux leading to underflow (Kirillin et al., 2012, 2015; Rizk et al., 2014). The warmer water (denser) from sidearm may intrude into the thermocline and generate internal waves (Maxworthy et al., 2002; Flynn \& Sutherland, 2004; Nash \& Moum, 2005).

We investigated $H 1$ by comparing the energy associated with convection, $E_{\text {conv }}(\mathrm{Eq} .8)$ to the energy stored in the short-period internal wave field, $E_{\mathrm{IW}}$ (Eq. 9). However, given the estimated convective decay time scale $(<4 \mathrm{~h})$, the $\sim 9 \mathrm{~h}$ time shift based on a cross correlation analysis between $E_{\text {conv }}$ (peak of $E_{\text {conv }}$ or $w_{\mathrm{c}}$ in phase with the peak of SR, not shown) and $E_{\mathrm{IW}}$ peaks seems too long to immediately conclude that the direct energy input from the convective plumes is entirely responsible for the peak in internal wave activity.

We first restrict the investigation of $H 1$ to daytime (10 am to $5 \mathrm{pm})$ and compute for this time interval the ratio of $E_{c o n v} / E_{I W}$ for the ten days period as the ratio between Eqs. 8 and 9, both in $\mathrm{J} \mathrm{m}^{-2}$. Results given in Fig. 8B indicate a distribution centred at $\sim 0.026 \pm 0.025$ with a large kurtosis. This value is close to that derived from the laboratory experiment of Ansong \& Sutherland (2010) who estimated that, on average, $4 \%$ of the energy flux associated from the convective plume was extracted by the internal waves.

Alternatively, we analyse $E_{\mathrm{IW}}$ as an integrator of the forcing (such as a capacitor integrates the electrical currents). From the temporal evolution of the thermal flux and the $E_{\mathrm{IW}}$ (Fig. 6), we can conclude that $E_{\mathrm{IW}}$ is building up as long as the heat flux is positive and reaches therefore its maximum when the heat flux goes
Fig. 8 A Daily maximum internal wave energy as a function of daily-averaged PAR. B Ratio of convective energy $\left(E_{\text {conv }}\right)$ to internal wave energy $\left(E_{\mathrm{IW}}\right)$ during daytime (10 am to $5 \mathrm{pm}$ )
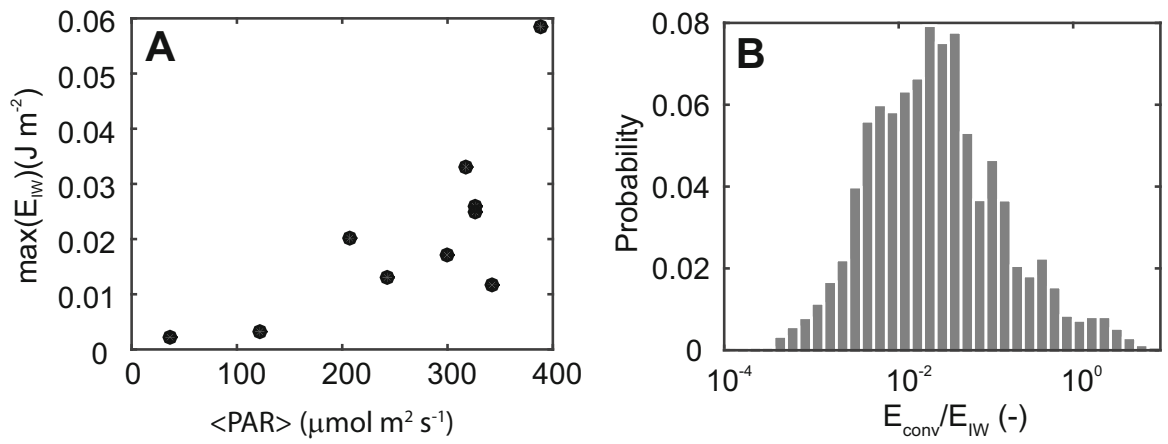
to zero. Similarly, the decay of $E_{\mathrm{IW}}$ stops as soon the thermal flux is starting in the morning (Fig. 6). Our results therefore suggests that $H 1$, or the direct energy extraction from the convective plumes impinging the thermocline is the key source of under-ice internal wave generation.

The long-time shift ( $\sim 9 \mathrm{~h}$ ) between $E_{\text {conv }}$ (or $I$ in Fig. 6) and $E_{\text {IW }}$ peaks also points to a remote source of internal wave activity. In ice-covered lakes, additional sources of internal wave energy are not obvious. Differential wind and pressure intensity on ice or energy released at the sloping boundaries by sediments after lake freezing have been shown to generate basin-scale internal waves (Bengtsson, 1996; Kirillin et al., 2009, 2012). Estimated periods of basin-scale internal waves for PB are too long to be associated with the observed oscillation of the thermocline. Recently, preferential lateral heating has been shown as a source of density current in the early winter due to heat released from the sediments (Rizk et al., 2014) and in the late winter due to higher heating from ice melting in the shoreline and the catchment (Kirillin et al., 2015). Such density current typically generates internal waves when reaching the thermocline (Flynn \& Sutherland, 2004) and could be a remote source of the observed oscillations. Ice thickness at the base camp remained constant over the ten days period $(40 \pm 1.3 \mathrm{~cm})$, while a transversal transect across the base camp conducted on 16 March 2015 (Kouraev, pers. comm.) showed that ice thickness was maximal around the measurement site and reduced by up to $20 \%(32 \mathrm{~cm})$ near the shore. Reduced ice thickness together with sediment heat release at the slope may lead to warmer (denser) temperature on the nearshore and generate underflow intruding the thermocline. An analysis of the short-term internal wave properties (Annex 2) suggests a phase speed of $\sim 0.06 \mathrm{~m} \mathrm{~s}^{-1}$. While we did not have any measurements to support the hypothesis of density currents intruding the thermocline and generating internal waves, we roughly estimate the propagation time for the internal wave to travel the $2 \mathrm{~km}$ distance from the shore to the base camp to $\sim 9 \mathrm{~h}$. This process could also partly explain the time shift between the peak in SR and the observed peak in internal wave activity. Our results therefore suggest that $H 2$ hypothesis, i.e. nearshore density current driven by solar radiation, could be responsible for energizing internal waves that propagate slowly offshore and for the peak in internal wave activities observed during the night. We encourage further experiments to fully investigate the potential role of density current generating internal waves in ice-covered lakes.

\section{Conclusions}

The first results of an interdisciplinary research program ('Life under Ice') are presented in this paper. The study reports results of a two-week intensive field campaign conducted on Lake Onega during the late winter. This period was characterized by an increase in solar radiation and an almost snow-free ice cover, thereby enabling an optimal volumetric heating of the below $4^{\circ} \mathrm{C}$ cold surface layer. For such conditions, we observed a daily convection mixing inside the water column down to $\sim 25 \mathrm{~m}$ flow depth.

In the absence of data from a high-resolution acoustic profiler, we estimated the vertical convective velocity by means of two independent methods. The dissipation-based method using a temperature microstructure profiler was thought to be the most accurate. However, low energetic conditions together with the potential energy contamination from other parallel research activities strongly affected the accuracy of some of the data and many casts were discarded. The external forcing solar radiation-based method accurately predicted the peak of the vertical convective velocity but the slow decay of the convective turbulence at dusk was not accounted for. Assuming an exponential decay of the energy, we suggest to use the decay estimate from Nieuwstadt \& Brost (1986) to parameterize the decay of the vertical convective velocity after the forcing ends.

The water column was also characterized by a thermocline below the convectively mixed layer. We observed evidence of a daily cycle of internal wave activity with energy peaking at night. Firstly, we hypothesized that the convective plume impinging the thermocline could transfer kinetic energy to the internal wave field. Over daytime, assuming that this process is the only source of energy for the internal waves, we calculated a ratio of kinetic energy from the convective plume to the potential energy embedded in the internal wave of $0.026 \pm 0.025$ (e.g. $\sim 3 \%$ ) which is surprisingly in agreement with the $4 \%$ value observed in the laboratory experiments of Ansong \& Sutherland (2010). This result suggests 
that convective plume can generate internal waves with a peak in internal waves activities at night after the end of solar radiation forcing. We secondly hypothesized that the internal wave activity is the result of differential heating near the shore leading to density flows intruding the thermocline and thereby generating internal waves (Flynn \& Sutherland, 2004). Although we could not formally observe this second process, the time lag between the maximum solar radiation and the maximum internal wave activity is consistent with the $\sim 2 \mathrm{~km}$ distance travelled by the fastest growing internal waves, assuming a phase speed of $0.06 \mathrm{~m} \mathrm{~s}^{-1}$ as calculated with the Taylor Goldstein equation.

Acknowledgements The present study was supported by the FEEL Foundation, "Fondation pour l'Etude des Eaux du Léman". The authors would like to thank Andrey Mitrokhov, Nikolay Palshin, Andrey Georgiev, Alexey Tolstikov, Andrey Balagansky and Maksim Potakhin (Northern Water Problems Institute, Karelian Research Centre, Russ. Acad. Sci.) for their efforts in collecting observational data. We also would like to thank Vasili Kovalenko the head of the expedition and Nikolay Filatov. First author thanks Marie-Elodie Perga for fruitful discussions and help in the field, and all scientists from the Life Under the Ice project (http://wiki.epfl.ch/ladoga). We finally thank the two anonymous reviewers for their very valuable comments.

\section{References}

Ansong, J. K. \& B. R. Sutherland, 2010. Internal gravity waves generated by convective plumes. Journal of Fluid Mechanics 648: 405-434.

Antenucci, J. P. \& J. Imberger, 2003. The seasonal evolution of wind/internal wave resonance in Lake Kinneret. Limnology and oceanography 48: 2055-2061.

Bengtsson, L., 1996. Mixing in ice-covered lakes. Hydrobiologia 322: 91-97.

Bouffard, D. \& L. Boegman, 2012. Basin scale internal waves. In Bengtsson, L., R. W. Herschy \& R. W. Fairbridge (eds.), Encyclopedia of Lakes and Reservoirs. Springer, Berlin: 102-107.

Bouffard, D. \& L. Boegman, 2013. A diapycnal diffusivity model for stratified environmental flows. Dynamics of Atmospheres and Oceans 61: 14-34.

Bouffard, D., L. Boegman \& Y. R. Rao, 2012. Poincaré waveinduced mixing in a large lake. Limnology and Oceanography 57: 1201-1216.

Bouffard, D., J. D. Ackerman \& L. Boegman, 2013. Factors affecting the development and dynamics of hypoxia in a large shallow stratified lake: Hourly to seasonal patterns. Water Resources Research 49: 2380-2394.

Cole, G. S. \& H. J. S. Fernando, 1998. Some aspects of the decay of convective turbulence. Fluid Dynamics Research 23: 161-176.
Cole, J. J., Y. T. Prairie, N. F. Caraco, W. H. McDowell, L. J. Tranvik, R. G. Striegl, C. M. Duarte, P. Kortelainen, J. A. Downing \& J. J. Middelburg, 2007. Plumbing the global carbon cycle: integrating inland waters into the terrestrial carbon budget. Ecosystems 10: 172-185.

Farmer, D. M., 1975. Penetrative convection in the absence of mean shear. Quarterly Journal of the Royal Meteorological Society 101: 869-891.

Flynn, M. R. \& B. R. Sutherland, 2004. Intrusive gravity currents and internal gravity wave generation in stratified fluid. Journal of Fluid Mechanics 514: 355-383.

Gill, A. E., 1982. Atmosphere-Ocean Dynamics. Academic Press, London.

Hampton, S. E., M. V. Moore, T. Ozersky, E. H. Stanley, C. M. Polashenski \& A. W. E. Galloway, 2015. Heating up a cold subject: prospects for under-ice plankton research in lakes. Journal of Plankton Research 37: 277-284.

Jonas, T., A. Stips, W. Eugster, \& A. Wüest, 2003a. Observations of a quasi shear-free lacustrine convective boundary layer: Stratification and its implications on turbulence. Journal of Geophysical Research: Oceans (1978-2012) 108: C10.

Jonas, T., A. Y. Terzhevik, D. V. Mironov \& A. Wüest, 2003b. Radiatively driven convection in an ice-covered lake investigated by using temperature microstructure technique. Journal of Geophysical Research 108: 3183.

Kang, D. \& O. Fringer, 2010. On the calculation of available potential energy in internal wave fields. Journal of Physical Oceanography 40: 2539-2545.

Karlsson, J., R. Giesler, J. Persson \& E. Lundin, 2013. High emission of carbon dioxide and methane during ice thaw in high latitude lakes. Geophysical Research Letters 40: 1123-1127.

Kelley, D. E., 1997. Convection in ice-covered lakes: effects on algal suspension. Journal of Plankton Research 19: 1859-1880.

Kirillin, G., C. Engelhardt, S. Golosov \& T. Hintze, 2009. Basinscale internal waves in the bottom boundary layer of icecovered Lake Müggelsee, Germany. Aquatic Ecology 43: 641-651.

Kirillin, G., M. Leppäranta, A. Terzhevik, N. Granin, J. Bernhardt, C. Engelhardt, T. Efremova, S. Golosov, N. Palshin, P. Sherstyankin, et al., 2012. Physics of seasonally icecovered lakes: a review. Aquatic Sciences 74: 659-682.

Kirillin, G. B., A. L. Forrest, K. E. Graves, A. Fischer, C. Engelhardt \& B. E. Laval, 2015. Axisymmetric circulation driven by marginal heating in ice-covered lakes. Geophysical Research Letters 42: 20142.

Malm, J., L. Bengtsson, A. Terzhevik, P. Boyarinov, A. Glinsky, N. Palshin \& M. Petrov, 1998. Field study on currents in a shallow, ice-covered lake. Limnology and oceanography 43: 1669-1679.

Matthews, P. C. \& S. I. Heaney, 1987. Solar heating and its influence on mixing in ice-covered lakes. Freshwater Biology 18: 135-149.

Maxworthy, T., J. Leilich, J. E. Simpson \& E. H. Meiburg, 2002. The propagation of a gravity current into a linearly stratified fluid. Journal of Fluid Mechanics 453: 371-394.

Mironov, D. V., S. D. Danilov \& D. J. Olbers, 2001. Large-eddy simulation of radiatively-driven convection in ice covered lakes. In Casamitjana, X. (ed.), Proceedings of the Sixth 
Workshop on Physical Processes in Natural Waters. University of Girona, Girona: 71-75.

Mironov, D., A. Terzhevik, G. Kirillin, T. Jonas, J. Malm \& D. Farmer, 2002. Radiatively driven convection in ice-covered lakes: Observations, scaling, and a mixed layer model. Journal of Geophysical Research 107: 7-16.

Nash, J. D. \& J. N. Moum, 2005. River plumes as a source of large-amplitude internal waves in the coastal ocean. Nature 437: 400-403.

Nieuwstadt, F. T. M. \& R. A. Brost, 1986. The decay of convective turbulence. Journal of the Atmospheric Sciences 43: 532-546.

Ostrovsky, I., Y. Z. Yacobi, P. Walline \& I. Kalikhman, 1996. Seiche-induced mixing: Its impact on lake productivity. Limnology and Oceanography 41: 323-332.

Petrov, M. P., A. Y. Terzhevik, R. E. Zdorovennov \& G. E. Zdorovennova, 2006. The thermal structure of a shallow lake in early winter. Water Resources 33: 135-143.

Rizk, W., G. Kirillin \& M. Leppäranta, 2014. Basin-scale circulation and heat fluxes in ice-covered lakes. Limnology and Oceanography 59: 445-464.

Salonen, K., M. Pulkkanen, P. Salmi \& R. W. Griffiths, 2014. Interannual variability of circulation under spring ice in a boreal lake. Limnology and Oceanography 59: 2121-2132.

Sander, J., A. Simon, T. Jonas \& A. Wüest, 2000. Surface turbulence in natural waters: a comparison of large eddy simulations with microstructure observations. Journal of Geophysical Research: Oceans 105: 1195-1207.

Schmid, M., M. D. Batist, N. G. Granin, V. A. Kapitanov, D. F. McGinnis, I. B. Mizandrontsev, A. I. Obzhirov \& A. Wüest, 2007. Sources and sinks of methane in Lake Baikal: A synthesis of measurements and modeling. Limnology and Oceanography 52: 1824-1837.

Sorbjan, Z., 1997. Decay of convective turbulence revisited. Boundary-Layer Meteorology 82: 503-517.

Stull, R. B., 1976. Internal gravity waves generated by penetrative convection. Journal of the Atmospheric Sciences 33: $1279-1286$.
Sun, C., W. D. Smyth \& J. N. Moum, 1998. Dynamic instability of stratified shear flow in the upper equatorial Pacific. Journal of Geophysical Research: Oceans 103: 1032310337.

Sutherland, B., 2010. Internal Gravity Waves. Cambridge University Press, Cambridge.

Townsend, A. A., 1964. Natural convection in water over an ice surface. Quarterly Journal of the Royal Meteorological Society 90: 248-259.

Tranvik, L. J., J. A. Downing, J. B. Cotner, S. A. Loiselle, R. G. Striegl, T. J. Ballatore, P. Dillon, K. Finlay, K. Fortino, L. B. Knoll, P. L. Kortelainen, T. Kutser, S. Larsen, I. Laurion, D. M. Leech, S. L. McCallister, D. M. McKnight, J. M. Melack, E. Overholt, J. A. Porter, Y. Prairie, W. H. Renwick, F. Roland, B. S. Sherman, D. W. Schindler, S. Sobek, A. Tremblay, M. J. Vanni, A. M. Verschoor, E. von Wachenfeldt \& G. A. Weyhenmeyer, 2009. Lakes and reservoirs as regulators of carbon cycling and climate. Limnology and Oceanography 54: 2298-2314.

Turner, J., 1973. Buoyancy effects in fluids. University Press, Cambridge: 403.

Vehmaa, A. \& K. Salonen, 2009. Development of phytoplankton in Lake Pääjärvi (Finland) during under-ice convective mixing period. Aquatic Ecology 43: 693-705.

Wüest, A. \& A. Lorke, 2003. Small-scale hydrodynamics in lakes. Annual Review of Fluid Mechanics 35: 373-412.

Wüest, A., \& M. Schmid, 2012. Physical Limnology Handbook of Environmental Fluid Dynamics, Volume One: Overview and Fundamentals. H. J. Fernando: pp. 153-168.

Wunsch, C., 1972. Bermuda sea level in relation to tides, weather, and baroclinic fluctuations. Reviews of Geophysics 10: 1-49.

Zdorovennov, R., N. Palshin, G. Zdorovennova, T. Efremova \& A. Terzhevik, 2013. Interannual variability of ice and snow cover of a small shallow lake. Estonian Journal of Earth Sciences 62: 26-32. 